\title{
PELUANG DAN TANTANGAN DALAM PEMANFAATAN TEKNOLOGI PENGINDERAAN JAUH DAN MACHINE LEARNING UNTUK PREDIKSI DATA TANAMAN PANGAN YANG LEBIH AKURAT
}

\author{
(Challenges And Opportunities In The Utilization Of Remote Sensing And Machine \\ Learning For Accurately Crop Plant Prediction)
}

Dwi Wahyu Triscowati ${ }^{1}$, Arie Wahyu Wijayanto ${ }^{2}$

\author{
BPS Kabupaten Banyuwangi ${ }^{1}$ \\ BPS RI ${ }^{2}$ \\ JL. KH. Agus Salim No 86-87, Banyuwangi \\ E-mail: trisco@bps.go.id
}

\begin{abstract}
ABSTRAK
Perubahan teknologi informasi menyebabkan terjadinya produksi data yang besar, cepat, dan berbagai macam. Pada era teknologi juga terjadi perkembangan pesat metode pengolahan data besar dan berdimensi tinggi seperti machine learning. Hal ini membuka peluang baru dalam penyediaan data statistik untuk berbagai permasalahan, seperti ketahanan pangan. Salah satu sumber big data gratis yang dapat dimanfaatkan untuk upaya ketahanan pangan adalah hasil penginderaan jauh. Penginderan jauh mengalami banyak kemajuan, yang tercermin dalam ketersediaan citra satelit dengan ketajaman pixel tinggi dan kaya informasi spasial temporal. Berbagai informasi vegetasi untuk prediksi tanaman pangan dapat diturunkan dari citra satelit ini. Namun, dibalik peluang yang ada, masih terdapat tantangan dalam pemanfaatan sepenuhnya citra satelit. Tujuan dari ulasan makalah ini adalah untuk mempelajari peluang dan tantangan dalam pemanfaatan teknologi penginderaan jauh dan machine learning untuk prediksi data tanaman pangan yang lebih akurat. Kami melihat ada banyak upaya penggunaan citra satelit untuk prediksi tanaman. Kami mengelompokkan metode yang digunakan untuk klasifikasi menjadi tiga kelompok, yaitu metode statistika konvensional, machine learning populer, dan deep learning. Sementara tantangan dalam pemanfaatan citra satelit yang teridentifikasi meliputi tantangan dari karakteristik citra satelit serta kondisi geografis dan pertanian di Indonesia. Lebih lanjut, hasil eksperimen kami sendiri menggunakan supervised random forest berdasarkan data multitemporal landsat 8, diperoleh bahwa pengambilan sampel, identifikasi kemungkinan seluruh kelas klasifikasi, serta rekayasa fitur berperan penting dalam peningkatan akurasi model klasifikasi. Dapat kami simpulkan bahwa ada peluang besar untuk pemantauan tanaman pangan menggunakan penginderaan jauh ini.
\end{abstract}

Kata kunci: penginderaan jauh, citra satelit, machine learning, prediksi tanaman pangan

\begin{abstract}
The information technology is changing rapidly and its cause the production of large, fast, and various kinds of data. In the era of technology, there is a rapid development of processing methods for large and high dimensions data, such as machine learning. This conditions causes a new opportunities in providing statistical data for various problems, such as food security. One free source of big data that can be used for food security is remote sensing. Remote sensing has many changing, which is reflected in the availability of satellite imagery with high pixel and rich temporal spatial information. Various vegetation information for food crop prediction can be derived. However, behind the opportunities, there are still challenges in using of remote sensing. The purpose of this review paper is to study the opportunities and challenges in the utilizing of remote sensing and machine learning for more accurately prediction of food crop. There are many research to use satellite imagery for crop prediction. We grouped the methods used for crop plant classification into three groups, conventional, popular machine learning, and deep learning. While the challenges in the utilizing of remote sensing is include challenges from the characteristics of remote sensing and challenges from geographical dan conditions of Indonesian agriculture. Furthermore, the results of our own experiments using supervised random forest based on multitemporal landsat 8, obtained that sampling, identification of the all possibility classes, as well as engineering features play an important role in increasing the accuracy of classification models. We can conclude that there are great opportunities for food crop monitoring using this remote sensing.
\end{abstract}

Keywords: remote sensing, satellite imagery, machine learning, crop plant prediction 


\section{PENDAHULUAN}

Ketahanan pangan sampai saat ini masih menjadi permasalahan pada negara berkembang dan tertinggal. World Bank menjadikan ketahanan pangan ini menjadi salah satu tujuannya dalam misi Suistanable Development Goals (SDGs), yaitu zero hunger (UNDP, 2015). Peningkatan produksi dalam negeri serta keseimbangan antara produksi dan kebutuhan pangan perlu menjadi perhatian agar ketahanan pangan dapat tercapai. Salah satu aspek penting untuk dapat mengevaluasi kedua perhatian tersebut adalah upaya penyediaan data statistik tanaman pangan melalui prediksi tanaman pangan. Jika prediksi tanaman pangan mampu dilakukan dengan akurat, bahkan sebelum adanya panen, maka proses menuju ketahanan pangan akan lebih mudah untuk dilakukan.

Upaya penyediaan data statistik tanaman pangan telah dilakukan oleh Badan Pusat Statistik (BPS) melalui metode survei, salah satunya dengan Survei Kerangka Sampel Area (KSA). KSA merupakan sebuah survei yang unit samplingnya berupa area kotak berukuran $300 \mathrm{~m} \times 300 \mathrm{~m}$. Sejumlah sampel diambil secara acak, lalu pengamatan fase tumbuh padi dilakukan setiap bulan terhadap 9 titik amatan pada tiap sampel terpilih. Luas panen dan potensi luas panen 3 bulan kedepan dapat diperoleh berdasarkan hasil pengamatan fase tumbuh padi tersebut (BPS, 2015).

Disisi lain, saat ini lanskap teknologi berubah dengan cepat dan sistem statistik nasional perlu dijaga kecepatan penyajian datanya agar tetap relevan. Pada era teknologi, data dan informasi terus berkembang dan penyediaan data dilakukan dengan sangat cepat. Sejumlah data besar setiap hari diproduksi, sebagian diantaranya dapat diperoleh dengan gratis. Salah satunya adalah data dari ruang angkasa hasil penginderaan jauh, yaitu citra satelit. Citra satelit yang diproduksi dalam sistem ruang, membuka peluang untuk menjadi sumber data statistik tanaman pangan. Upaya prediksi tanaman pangan menggunakan citra satelit gratis telah populer di kalangan komunitas penginderaan jauh karena citra satelit ini memiliki banyak informasi vegetasi yang potensial untuk digunakan dalam klasifikasi tanaman pangan (Azar et al., 2016; Blasiak, 2014). Metode pengumpulan data dengan cara tradisional saja, terasa semakin tidak efektif, karena hasil pengolahan citra satelit dapat terukur, real time, dan relatif murah untuk klasifikasi tanaman pangan. Perkembangan machine learning juga membantu pengolahan data besar dan berdimensi tinggi seperti citra satelit ini.

Terdapat peluang besar pemanfaatan penginderaan jauh dan machine learning untuk prediksi tanaman pangan menggunakan citra satelit. Prediksi tanaman pangan menggunakan citra satelit salah satunya dilakukan dengan cara membuat klasifikasi tanaman pangan pada lokasi tertentu berdasarkan informasi dari gambar citra satelit. Contohnya adalah klasifikasi fase tanam padi, klasifikasi jenis tutupan lahan, klasifikasi tanaman tebu yang sehat dan terserang penyakit, klasifikasi jenis tanaman hutan tertentu, dsb. Kami mengamati bahwa secara umum terdapat tiga kelompok metode dalam membentuk klasifikasi citra satelit, yaitu statistika konvesional, machine learning populer, dan deep learning. Setiap metode memiliki kelebihan dan kekurangan masing-masing yang dapat membantu upaya prediksi tanaman pangan.

Meskipun citra satelit memiliki peluang untuk prediksi tanaman, ada beberapa tantangan yang perlu dihadapi dalam pemanfaatannya. Contohnya masa tanam dan jenis tanaman yang sangat bervariasi memerlukan fitur yang tepat untuk meningkatkan akurasi model. Agar kita dapat memanfaatkan citra satelit sebaik mungkin, maka kita perlu mengidentifikasi tantangan apa saja dalam pemanfaatan citra satelit hasil penginderaan jauh ini. Oleh karenanya, dalam ulasan makalah ini, kami ingin mempelajari peluang dan tantangan dalam pemanfaatan teknologi penginderaan jauh dan machine learning untuk prediksi data tanaman pangan yang lebih akurat.

\section{PENGINDERAAN JAUH DAN MACHINE LEARNING}

Pertumbuhan perkotaan dan penduduk yang dinamis berkaitan erat dengan ancaman terhadap lahan pertanian dan ketahanan pangan. Perkiraan berbasis penginderaan jauh dianggap sebagai sumber yang tepat untuk memantau perubahan dinamis ini dalam jangka panjang. Penyediaan data tentang kondisi perubahan perkotaan, lahan pertanian, dan 
berbagai aspek pertanian yang terkait dengan ketahanan pangan menuntut adanya perkembangan metodologi-metodologi baru, diantaranya adalah perkembangan jenis penginderaan jauh yang digunakan dan metode statistika dalam pengolahan data pengindrraan jauh tersebut.

Teknologi penginderaan jauh saat ini terus mengalami perkembangan yang pesat. Semakin banyak satelit diluncurkan dengan jenis sensor yang lebih canggih. Berbagai jenis citra satelit diproduksi dengan tingkat ketajaman pixel, periode, dan kanal band yang berbeda-beda.

Semakin tinggi ketajaman pixel dan semakin banyak band yang dimiliki, ukuran data citra satelit menjadi semakin besar dan berdimensi tinggi. Hal ini menuntut metode statistika untuk semakin berkembang. Pengolahan data besar dan dimensi tinggi merupakan tantangan bagi para pengguna machine learning. Ketersediaan data label yang terbatas juga memerlukan pengembangan metode-metode yang mampu melakukan klasifikasi dengan jumlah label terbatas.

Klasifikasi terhadap citra satelit ini dapat dilakukan dengan menggunakan metode regresi, clustering, ataupun klasifikasi secara langsung. Klasifikasi tanpa menggunakan model klasifikasi secara langsung dilakukan dengan dua tahap, pertama pembentukan model, kedua penurunan batas kelas klasifikasi dari model yang terbentuk. Berdasarkan perkembangan komputasional, kami mengelompokkan metode statistika untuk klasifikasi citra satelit menjadi tiga kelompok metode.

\section{Metode Statistika Konvensional}

Kelompok metode statistika konvensional terdiri dari metode regresi, klasifikasi tidak terbimbing, maupun klasifikasi terbimbing dengan ciri klasifikasi dilakukan menggunakan fitur terbatas. Pada sebagian kelompok ini, cutting point kelas klasifikasi tidak ditentukan secara otomatis oleh model klasifikasi. Contoh kelompok ini adalah regresi kuadratik, regresi kubik, maximum likelihood, nearest neighbor, klasifikasi berdasarkan algoritma clustering.

Pada kelompok ini, klasifikasi dilakukan berdasarkan satu fitur tertentu yang dianggap sangat berkaitan erat dengan kelas klasifikasi, dan informasi tambahan dari beberapa fitur yang lain. Misalkan klasifikasi fase tumbuh padi dilakukan dengan membuat regresi kuadratik antara fitur EVI dengan umur Hari Sebar Tanam (HST) padi, kemudian dari hasil regresi tersebut dibentuk batas kelas klasifikasi (Dirgahayu et al., 2015; Parsa, Dirgahayu, Manalu, Carolita, \& KH, 2017). EVI merupakan indeks tingkat kehijauan tanaman yang dipercaya sebagai salah satu fitur terbaik pembeda tanaman. Informasi lain ditambahkan berdasarkan pengamatan bahwa ciri saat fase awal tanam adalah tergenang air dicirikan dengan nilai fitur NDWI tinggi, dan ciri saat fase panen adalah lahan kering dicirikan dengan nilai fitur NDBI tinggi. Klasifikasi lainnya misalkan klasifikasi tutupan lahan menggunakan maximum likelihood. Pengklasifikasian tiap kelas ditentukan menggunakan kemungkinan maximum nilai RGB berdasarkan nilai RGB data sampel tiap kelas.

Kunci dari kelompok ini adalah penggunaan fitur yang tepat karena terbatasnya jumlah fitur yang digunakan. Padahal citra satelit memiliki beberapa fitur utama dan puluhan fitur turunan. Fitur turunan dapat diperoleh dari kombinasi antar band, kombinasi antar periode, ataupun gabungan keduanya. Oleh karenanya sejumlah metode ekstraksi fitur, seperti analisis komponen utama, analisis derivatif dan analisis wavelet, banyak digunakan untuk menyederhanakan fitur ataupun memilih fitur turunan terbaik (Onojeghuo \& Blackburn, 2011). Alfredo R Huete dalam beberapa penelitiannya telah menurunkan fitur pembeda tanaman dari dua atau tiga kanal band, serta dari sudut kemiringan pancaran spektral tanaman antara dua band dalam sebuah ruang spektral seperti EVI. Kemudian dilakukan pengembangan lagi berupa indeks EVI tanpa band blue (Jiang, Huete, Didan, \& Miura, 
2008). Untuk menurunkan fitur-fitur tersebut, tentu dibutuhkan proses yang intensif dan keahlian ilmu tentang penginderaan jauh. Peneliti lainnya, Thenkabail et al. meyakini bahwa sekitar 3-8 band sempit citra satelit biasanya cukup untuk membangun model prediktif biofisik tanaman, dan band lebih lanjut tidak diperlukan karena dianggap menyebabkan noise pada proses klasifikasi (Thenkabail, Gumma, Teluglunta, \& Mohammed, 2014). Sehingga pada kelompok ini sejumlah penelitian dilakukan untuk memahami karakteristik utama vegetasi berdasarkan pancaran spektral suatu citra satelit.

Seiring kelas klasifikasi yang semakin rumit dan akurasi yang rendah jika menggunakan satu periode citra saja sebagai fiturnya, berkembanglah penelitian yang menggunakan beberapa periode citra. Penelitian tersebut berupa pengenalan profil spektral tanaman berdasarkan musim. Dari sini kemudian dikenal pola spektral temporal suatu tanaman dalam satu periode musim tanam. Misalkan pola spektral EVI pada tanaman di hutan cenderung datar sepanjang tahun, sementara tanaman padi polanya naik kemudian turun membentuk kurva kubik dalam satu musim tanam (Dirgahayu et al., 2015). Penyelidikan pola spektral ini perlu dilakukan dengan turun lapangan secara langsung untuk melihat pancaran spektral suatu tanaman dalam satu musim tanam. Suatu jenis tanaman tertentu akan mewakili karakteristik spektral yang berbeda ataupun mengikuti profil spectral temporal yang unik.

Tabel 1. Beberapa Contoh Metode Statistika Konvensional Untuk Klasifikasi Gambar Citra Satelit

\begin{tabular}{|c|c|c|c|c|c|}
\hline No & Penulis & Metode & $\begin{array}{l}\text { Jenis Citra } \\
\text { Satelit }\end{array}$ & Kelas klasifikasi & Akurasi atau $\mathrm{R}^{2}$ \\
\hline 1 & $\begin{array}{l}\text { (Guan, } \\
\text { Huang, Liu, } \\
\text { Meng, \& } \\
\text { Liu, 2016), } \\
\text { Vietnam }\end{array}$ & $\begin{array}{l}\text { Time-Series } \\
\text { clustering } \\
\text { dengan jarak } \\
\text { DTW }\end{array}$ & MODIS & $\begin{array}{l}\text { Lahan padi, bukan } \\
\text { lahan padi }\end{array}$ & $\begin{array}{l}\text { - } \mathrm{R}^{2} \text { pada pada luasan nasional } \\
\text { sebesar 0,809. } \\
\text { - } \mathrm{R}^{2} \text { pada luasan } 500 \mathrm{~km}^{2} \mathrm{~s} / \mathrm{d} 1000 \\
\mathrm{~km}^{2} \text { sebesar } 0,226\end{array}$ \\
\hline 2 & $\begin{array}{l}\text { (Dirgahayu, } \\
\text { Parsa, \& } \\
\text { Carolita, } \\
\text { 1997), } \\
\text { Indonesia }\end{array}$ & $\begin{array}{l}\text { Maximum } \\
\text { likelihood }\end{array}$ & $\begin{array}{l}\text { Radar ERS- } \\
1 \text { SAR }\end{array}$ & $\begin{array}{l}\text { Air/rawa, } \\
\text { pemukiman, padi, } \\
\text { tebu, kebun } \\
\text { campur }\end{array}$ & $\begin{array}{l}\text { - Akurasi klasifikasi tebu sebesar } \\
89,8 \% \\
\text { - Akurasi pemetaan sebesar } \\
\text { 78,3\% }\end{array}$ \\
\hline 3 & $\begin{array}{l}\text { (Parsa et } \\
\text { al., 2017), } \\
\text { Indonesia }\end{array}$ & Regresi kubik & $\begin{array}{l}\text { Modis dan } \\
\text { Landsat-8 }\end{array}$ & $\begin{array}{l}\text { Air, bera, vegetatif } \\
\text { awal, veg. akhir, } \\
\text { generatif awal, } \\
\text { generatif akhir }\end{array}$ & $\begin{array}{l}\text { - } \mathrm{R}^{2} \text { regresi } 94,25 \mathrm{~s} / \mathrm{d} \text { 99,15 } \\
\text { - Akurasi pengujian lapangan } 53 \% \\
\mathrm{~s} / \mathrm{d} 59 \% \text {, dan } 86 \% \text { ketika MODIS } \\
\text { di smooting dulu }\end{array}$ \\
\hline
\end{tabular}

Secara umum, penelitian pada metode konvensional dilakukan dengan intensif dalam penyelidikan karakteristik citra satelit. Misalkan Noviar et al. menguji respon spektral menggunakan alat spektometer lalu dilakukan analisis pola spektral pada setiap umur padi. Dari hasil penelitian diperoleh informasi bahwa nilai reflektansi band NIR (750-900mm) lebih tinggi pada fase generatif dibandingkan fase vegetatif. Pada fase vegetatif nilai reflektansi NIR umumnya sekitar 35\%, sedangkan pada fase generatif sekitar $40 \%$. Reflektansi yang tidak teratur atau tidak akurat dapat disebabkan dari gangguan pengukuran lapangan maupun gangguan citra landsat-8. Gangguan pengukuran lapangan adalah adanya gangguan pada alat ataupun pengukuran dilakukan pada cuaca yang mendung atau menjelang sore. Gangguan pada Landsat-8 dapat disebabkan kondisi data yang tidak bersih seperti tertutup awan tipis (haze) sehingga mempengaruhi nilai reflektansi tanaman (Noviar, Dirgahayu, Anwar, \& Indriyawan, 2015).

Dari hasil penelitian kelompok ini, kita akan mendapatkan informasi detail tentang indeks-indeks terkait tanaman tertentu dan pola spektral temporal fitur pada suatu jenis tanaman, karena pengamatan terhadap fitur tertentu terkait tanaman dilakukan secara mendalam. Informasi awal ini akan berguna untuk menurunkan fitur-fitur pada metode machine learning populer, serta 
memberikan informasi untuk analisis pada metode deep learning. Tanpa informasi dari kelompok ini, kelompok machine learning popular akan kesulitan untuk menurunkan fitur-fitur baru.

Keterbatasan metode statistika konvensional adalah rendahnya akurasi klasifikasi ketika model yang terbentuk digunakan untuk memprediksi area yang luas dan tidak ditanami dengan tanaman terpilih saja. Perkembangan penelitian pola spektral temporal tanaman berdasarkan masa tanamnya, juga tidak dapat secara langsung dimasukkan ke dalam model untuk meningkatkan akurasi. Hal ini dikarenakan klasifikasi hanya dapat dilakukan dengan satu-dua fitur saja.

\section{Metode Machine Learning Populer}

Kelompok machine learning popular terdiri dari kelompok metode dengan ciri fitur yang digunakan lebih banyak, kemampuan menangani data yang lebih kompleks, dan penyelidikan yang mendalam untuk peningkatan akurasi model. Contoh kelompok ini adalah decision tree, SVM, random forest, bagging, boosting, dan neural network.

Pada kelompok kedua ini, klasifikasi dilakukan secara langsung oleh model berdasarkan panduan data label dari sampel. Misalnya Millard dan Richardson melakukan pemetaan ekosistem lahan gambut dengan kelas pertanian, rawa, hutan, semak belukar di rawa, dan pohon di rawa menggunakan random forest. Mereka menyelidiki apakah kesalahan klasifikasi tiap kelas saling independen, adanya kesamaan proporsi kesalahan klasifikasi tiap kelas, serta apakah pemilihan data pelatihan dan fitur input yang spesifik berdampak besar terhadap akurasi total (Millard \& Richardson, 2015).

Tabel 2. Beberapa Contoh Metode Machine Learning Populer Untuk Klasifikasi Gambar Citra Satelit

\begin{tabular}{|c|c|c|c|c|c|}
\hline $\begin{array}{l}N \\
0\end{array}$ & Penulis & Metode & $\begin{array}{c}\text { Jenis Citra } \\
\text { Satelit }\end{array}$ & Kelas klasifikasi & Akurasi atau R2 \\
\hline 1 & $\begin{array}{l}\text { (Asgarian, } \\
\text { Soffianian, \& } \\
\text { Pourmanafi, } \\
\text { 2016), Iran }\end{array}$ & $\begin{array}{l}\text { Decisions } \\
\text { Tree dan } \\
\text { SVM }\end{array}$ & Landsat-8 & $\begin{array}{l}\text { Gandum, Kentang, } \\
\text { Barley, Alfalfa, } \\
\text { padi, sayuran, } \\
\text { pohon rumah kaca }\end{array}$ & $\begin{array}{l}\text { - Akurasi musim summer crops } \\
\text { sebesar } 92,36 \% \\
\text { - Akurasi musim Spring crops } \\
\text { sebesar } 91,56 \%\end{array}$ \\
\hline 2 & $\begin{array}{l}\text { (Clark, } \\
\text { 2017), USA }\end{array}$ & $\begin{array}{l}\text { Multiple } \\
\text { Endmember } \\
\text { Spektral } \\
\text { Mixture } \\
\text { Analysis } \\
\text { (MESMA) dan } \\
\text { Random } \\
\text { Forests (RF) }\end{array}$ & $\begin{array}{l}\text { HyspIRI, } \\
\text { Landsat 8, } \\
\text { dan } \\
\text { Sentinel-2 }\end{array}$ & $\begin{array}{l}\text { Rawa pasang surut, } \\
\text { Pohon musim } \\
\text { gugur berdaun } \\
\text { lebar, Semak } \\
\text { belukar, Tanaman } \\
\text { tahunan, } \\
\text { Perkotaan, Lahan } \\
\text { Terbangun, Bera } \\
\text { Rerumputan, dll }\end{array}$ & $\begin{array}{l}\text { - Rata-rata akurasi summer lebih } \\
\text { kecil daripada multiseasonal } \\
\text { - Rata-rata akurasi berdasarkan } \\
\text { polygon lebih besar daripada } \\
\text { pixel } \\
\text { - Rata-rata akurasi RF lebih besar } \\
\text { daipada MESMA } \\
\text { - RF multiseasonal berdasarkan } \\
\text { polygon }=83,2 \% \mathrm{~s} / \mathrm{d} 85,0 \%\end{array}$ \\
\hline 3 & $\begin{array}{l}\text { (Teluglunta } \\
\text { et al., 2018), } \\
\text { China dan } \\
\text { Australia }\end{array}$ & $\begin{array}{l}\text { Random } \\
\text { forest on } \\
\text { Google Earth } \\
\text { Engine (GEE) }\end{array}$ & $\begin{array}{l}\text { Landsat } 7 \\
\text { and } \\
\text { Landsat } 8\end{array}$ & $\begin{array}{l}\text { lahan pertanian, } \\
\text { padang rumput, } \\
\text { bukan lahan } \\
\text { pertanian }\end{array}$ & $\begin{array}{l}\text { - Akurasi area Australia sebesar } \\
\text { 97,6\% } \\
\text { - Akurasi } 4 \text { area di China antara } \\
\text { 91,6\% s/d 97,7\% }\end{array}$ \\
\hline 4 & $\begin{array}{l}\text { (Park et al., } \\
\text { 2018), Korea }\end{array}$ & SVM dan & $\begin{array}{l}\text { ALOS } \\
\text { Palsar, } \\
\text { Landsat 5, } \\
\text { SRTM } \\
\text { DEM, } \\
\text { Radarsat-1 }\end{array}$ & $\begin{array}{l}\text { Site A (Homogen): } \\
\text { lahan terbangun, } \\
\text { padi, lahan } \\
\text { terbuka, tumbuh- } \\
\text { tumbuhan, tanah } \\
\text { bera, air } \\
\text { Site B (Heterogen): } \\
\text { lahan terbangun, } \\
\text { padi, lahan } \\
\text { terbuka, hutan } \\
\text { rumput, lahan } \\
\text { basah, tanah bera, } \\
\text { air }\end{array}$ & $\begin{array}{l}\text { - Citra SAR tidak ideal untuk } \\
\text { daerah yang kasar dan tutupan } \\
\text { lahan yang heterogen, jika difusi } \\
\text { dengan Landsat mampu } \\
\text { meningkatkan akurasi } \\
\text { - Akurasi daerah heterogen lebih } \\
\text { rendah daripada homogen } \\
\text { - Akurasi kelas binari lebih tinggi } \\
\text { daripada kelas multiclas } \\
\text { - Akurasi site B dengan RF } \\
\text { multiclass } 71 \% \mathrm{~s} / \mathrm{d} 88 \% \\
\text { - Akurasi site B dengan SVM } \\
\text { multiclass } 72,67 \% \mathrm{~s} / \mathrm{d} 88,67 \%\end{array}$ \\
\hline
\end{tabular}


5 (Fathoni, Chulafak, \& Kushardono, 2017), Indonesia
Radar Sawah, badan air/tambak, lahan terbangun

\begin{tabular}{|c|c|c|}
\hline $\begin{array}{l}\text { Maximum } \\
\text { likelihood dan } \\
\text { Neural }\end{array}$ & $\begin{array}{l}\text { Radar } \\
\text { Sentinel-1 } \\
\text { SAR }\end{array}$ & $\begin{array}{l}\text { Sawah, badan } \\
\text { air/tambak, lahan } \\
\text { terbangun }\end{array}$ \\
\hline
\end{tabular}

- Akurasi semua fitur tekstur $78 \%$, fitur kontras saja $88 \%$

- Akurasi neural network $88 \%$, maximum likelihood $84 \%$

Jumlah fitur yang digunakan kelompok ini berasal dari beberapa fitur dari satu periode citra satelit, satu fitur time series dari beberapa periode citra, berbagai kombinasi fitur dari beberapa citra satelit satu periode, dan berbagai fitur timeseries dan kombinasi antar citra. Fathoni et al. menggunakan fitur-fitur GLCM dari citra RADARSAT berupa ASM, contrast, correlation, dissimilarity, energy, entropy, homogeneity, MAX, mean, variance sebagai input neural network untuk memetakan lahan sawah (Fathoni et al., 2017). Sementara Park et al. menggunakan fitur backscattering dari citra ALOS PALSAR multitemporal, band $1 \mathrm{~s} / \mathrm{d}$ band 5, band 7, NDVI, dan NDWI dari landsat 5 multitemporal, elevation citra SRTM DEM, dan backscattering dari RADARSAT 1 multitemporal (Park et al., 2018).

Keunggulan kelompok machine learning populer adalah akurasi model biasanya lebih tinggi, kemampuan menangani daerah yang lebih heterogen, dan cutting point kelas klasifikasi tidak dilakukan secara manual tetapi ditentukan oleh model klasifikasi secara langsung. Akurasi yang lebih tinggi dan kemampuan menangani daerah heterogen disebabkan adanya kombinasi dari beberapa fitur sehingga model lebih dapat menangkap informasi dari setiap kelas. Keunggulan lainnya karena kelompok ini dapat menggunakan banyak fitur, maka penyelidikan fitur-fitur turunan pembeda kelas dapat dilakukan. Pada penelitian Fathoni et al. jika model menggunakan fitur contrast saja, akurasi model lebih tinggi daripada jika memakai keseluruhan fitur tekstur. Lebih lanjut, akurasi klasifikasi menggunakan neural network lebih tinggi daripada akurasi maximum likelihood (Fathoni et al., 2017). Sementara pada penelitian Park et al. diperoleh bahwa dari 6 skenario fitur yang digunakan, rata-rata akurasi klasifikasi di area $\mathrm{A}$ (homogen), lebih tinggi daripada di area $\mathrm{B}$ (heterogen), baik menggunakan SVM maupun RF (Park et al., 2018).

Kelemahan metode machine learning popular adalah jumlah sampel harus banyak dan proses yang lama dalam seleksi kombinasi set fitur terbaik. Penyelidikan harus dilakukan dengan sekian banyak kombinasi fitur untuk mendapatkan set fitur terbaik. Masing-masing metode machine learning juga memiliki keunggulan dan kelemahan. SVM dikenal bekerja dengan baik dalam ruang fitur berdimensi besar, sehingga kinerja SVM mungkin akan lebih baik daripada RF. Namun RF dikenal tidak sensitif terhadap korelasi antar fitur karena prinsip permutasi invariant. Pada data dengan jumlah fitur yang sangat banyak, dimungkinkan adanya korelasi pada fitur (Ghimire, Rogan, Galiano, Panday, \& Neeti, 2012).

\section{Metode Deep Learning}

Kelompok ketiga adalah kelompok deep learning seperti deep Gaussian, CNN, RNN, LSTM, reinforced, dan transfer learning (Kamilaris \& Bold, 2018; Lu \& Zhang, 2018; Liu, Zhong, Fei, Zhu, \& Qin, 2018). Deep learning ini baru mulai berkembang pesat pada tahun 2015 saat komputasional semakin canggih. Kelompok ini dicirikan dengan proses klasifikasi dengan inputnya langsung berupa gambar dan data label. Gambar citra input dimasukkan ke dalam model beserta data labelnya, lalu model memilih sendiri kombinasi fitur terbaik pembeda tanaman untuk membentuk model klasifikasi.

Deep learning merupakan bagian dari machine learning dengan model pembelajaran yang lebih deep (dalam). Contohnya Convolutional Neural Network (CNN) merupakan pengembangan dari Neural Network (NN), dimana pada bagian hidden layernya diberikan pembelajaran lagi misalkan dengan convolutional-relu dan pooling. Ketika kita memasukkan input berupa tumpukan gambar band citra satelit berukuran nxn pixel dan data labelnya, model akan mengekstrak sendiri nilai pixel dari setiap image per band, lalu membentuk kombinasi nilainya untuk membentuk model. Sehingga saat kita menggunakan deep learning, kita cukup memasukkan tumpukan band tersebut dengan ukuran tertentu sebagai inputnya. Kita tidak perlu mengekstrak nilai band, menambahkan fitur-fitur temporal, indeks-indeks yang diyakini membedakan tanaman, ataupun menurunkan fitur-fitur baru dari pola data seperti pada kelompok machine learning (Zhang, Xu, \& Fraundorfer, 2017; Zhu et al., 2017). 
Tabel 3. Beberapa Contoh Metode Deep Learning Untuk Klasifikasi Gambar Citra Satelit

\begin{tabular}{|c|c|c|c|c|c|}
\hline 0 & Penulis & Metode & $\begin{array}{c}\text { Jenis Citra } \\
\text { Satelit }\end{array}$ & Kelas klasifikasi & Akurasi atau R2 \\
\hline 1 & $\begin{array}{l}\text { (Tong, Xia, } \\
\text { Lu, Shen, \& } \\
\text { Li, 2018), } \\
\text { China }\end{array}$ & $\begin{array}{l}\text { Deep } \\
\text { transf } \\
\text { deng }\end{array}$ & $\begin{array}{l}\text { Berbagai } \\
\text { citra satelit } \\
\text { resolusi } \\
\text { tinggi }\end{array}$ & $\begin{array}{l}\text { an, hutan, } \\
\text { rumput, }\end{array}$ & $\begin{array}{l}\text {-Akurasi tertinggi ukuran multiscale } \\
95,74 \% \text { menggunakan machine } \\
\text {-Jika menggnating dengan } \\
\text { learning tertingi } \\
\text { RF+fusion } 84,75 \%\end{array}$ \\
\hline 2 & $\begin{array}{l}\text { (You, } \\
\text { Low, } \\
\& \text { Erm } \\
\text { 2017) }\end{array}$ & $\begin{array}{l}n \\
n \\
(G P)\end{array}$ & $\begin{array}{l}\text { Modis, } \\
\text { Landcover, } \\
\text { Temperatur }\end{array}$ & $\begin{array}{l}\text { Tanaman pangan } \\
\text { seperti kedelai, } \\
\text { jagung, gandum, } \\
\text { beras }\end{array}$ & $\begin{array}{l}\text {-Nilai RMSE ridge regression 7,97; } \\
\text { Decision tree 7,73; DNN 8,32; } \\
\text { LSTM 6,27; LSTM + GP 5,83; CNN } \\
5,77 ; \text { CNN + GP 5,55 }\end{array}$ \\
\hline 3 & $\begin{array}{l}\text { (Tao, Xu, } \\
\text { Lu, \& } \\
\text { Zhong, } \\
\text { 2018), } \\
\text { China }\end{array}$ & $\begin{array}{l}\text { Depth-width- } \\
\text { reinforced } \\
\text { DNN }\end{array}$ & $\begin{array}{l}\text { BJ02, } \\
\text { GF02, } \\
\text { geoeye, } \\
\text { dan } \\
\text { quickbird }\end{array}$ & $\begin{array}{l}\text { Perairan, Pohon, } \\
\text { Lahan Bera, } \\
\text { Bangunan, Jalan }\end{array}$ & $\begin{array}{l}\text { - Akurasi keseluruhan ataupun } \\
\text { perkelas di atas } 97 \% \\
\text { - Rata-rata akurasi tertinggi ketika } \\
\text { memakai } 3 \text { subnet dan terendah } \\
\text { ketika tanpa DenseNet }\end{array}$ \\
\hline
\end{tabular}

Keunggulan kelompok ini adalah akurasi tinggi dan seleksi fitur tidak dilakukan secara manual atau hand crafted fitur seperti kelompok pertama dan kedua. Dengan perkembangan penginderaan jauh, data citra satelit menjadi sangat bervariasi sehingga deep learning menjadi alternatif agar secara otomatis mempelajari fitur-fitur bermanfaat dari set data mentah citra satelit yang sangat besar. Deep learning menjadi alat baru dan menarik yang dapat menjadi tren selanjutnya dalam pengembangan pemrosesan gambar penginderaan jauh (Zhang et al., 2016).

Kelemahan kelompok ini adalah jumlah sampel yang diperlukan jauh lebih banyak bahkan dibandingkan kelompok kedua, kebenaran data label berpengaruh terhadap model, komputasi lebih rumit, dan model yang tidak dikenali atau black box. Padahal ketersediaan data label sangat terbatas. Jika kita akan menyediakan banyak data label, perlu dilakukan survei lapangan yang berarti menggunakan biaya. Tantangan ini menyebabkan jenis deep learning semakin berkembang, misalkan deep learning transferable dan reinforced deep learning yang tidak membutuhkan data label sebanyak deep learning pada umumnya (Tong et al., 2018).

\section{TANTANGAN PEMANFAATAN PENGINDERAAN JAUH}

Ketersediaan informasi yang akurat dan tepat waktu mengenai pertanian sangat penting dalam memastikan ketahanan pangan. Oleh karenanya, akses pada data penginderaan jauh gratis, seperti Sentinel-1, Sentinel-2, Landsat, dan Modis membuka peluang pemantauan tanaman pangan. Keuntungan penginderaan jauh adalah sifat sinoptik dan berulang yang memberikan informasi spasial termporal berkelanjutan tentang pertumbuhan tanaman (Fritz et al., 2018).

Dibalik peluang penggunaan citra satelit sebagai sumber data, terdapat beberapa tantangan yang perlu dihadapi. Di Indonesia, dua tantangan utama pemanfaatan data citra satelit dapat berasal dari karakteristik citra satelit sendiri maupun dari pola pertanian dan kondisi geografis Indonesia. Tantangan dari citra satelit meliputi adanya tutupan awan dan kompleksitas data.

Citra satelit terdiri dari citra optik yang tidak tembus awan dan citra radar yang tembus awan. Citra optik seperti landsat-8, sentinel-2, dan Modis memiliki banyak band yang mampu menjadi sumber informasi vegetasi, namun banyak mengalami tutupan awan terutama pada daerah pegunungan dan berawan tinggi. Kondisi geografis Indonesia dengan jumlah awan yang merata, menyebabkan citra satelit optik di seluruh wilayah Indonesia pernah mengalami adanya tutupan awan ataupun kabut awan (haze). Citra radar, seperti radar Sentinel-1 mampu menembus awan, namun jumlah band yang tersedia masih terbatas dan relatif belum banyak penelitian klasifikasi tanaman pangan menggunakan radar Sentinel-1 ini. Oleh karenanya, dari citra Sentinel-1 belum banyak diperoleh informasi fitur pembeda tanaman. 
Kompleksitas gambar citra satelit berbeda dengan gambar citra biasa seperti foto kamera. Gambar citra satelit merupakan pancaran spektral dari objek di bumi. Misalkan landsat-8 terdiri dari band aerosol, Red, Green, Blue, NIR, SWIR 1, SWIR 2, TIR. Sementara gambar foto hanya terdiri dari rgb. Cakupan gambar citra satelit juga heterogen, mencakup berbagai jenis objek dengan ukuran, warna, dan lokasi yang berbeda dalam satu gambar. Padahal antar objek yang berbeda dapat memiliki tampilan yang mirip. Misalkan terkadang kita tidak yakin warna kecoklatan pada citra satelit apakah berasal dari atap bangunan atau lahan terbuka.

Tantangan lainnya, gambar bumi yang ditangkap oleh citra satelit bukan dalam bentuk satu gambar utuh, tetapi terpotong-potong menjadi beberapa scenes, dimana tiap scenes memiliki tanggal penangkapan yang berbeda. Agar model yang dihasilkan akurat, sedapat mungkin data label yang digunakan memiliki tanggal yang sama atau sangat mendekati tanggal citra satelit. Jika terjadi perbedaan, perlu dilakukan pengecekan berapa rentang waktu perbedaan antara data label dan citra satelit yang diperkirakan tidak berpengaruh terhadap nilai fitur.

Prediksi tanaman juga sedikit berbeda dengan prediksi bangunan. Prediksi tanaman pangan adalah prediksi dinamis yang melihat perubahan antar waktu. Sehingga setelah dilakukan prediksi pada masing-masing citra tiap periode, perlu dideteksi kekonsistenan perubahan antar waktu pada lokasi yang sama. Misalkan jika suatu lokasi awalnya terprediksi sebagai padi fase vegetatif awal, maka akan dianggap tidak konsisten jika periode selanjutnya terprediksi sebagai fase panen. Selain itu, tanaman pangan mengalami proses perubahan yang cepat. Walaupun akurasi prediksi untuk akhir tanam cukup tinggi, belum tentu di awal tanam juga tinggi karena adanya perubahan fitur yang cukup besar. Padahal rata-rata pertanian di Indonesia sangat bervariasi baik masa tanam maupun jenis tanamannya. Awal tanam yang berbeda-beda berarti fase tanam tiap lokasi menjadi berbeda-beda. Kemudian biasanya dalam satu lokasi selama satu tahun ditanami dengan jenis tanaman yang berselang-seling. Contohnya pada suatu lawan sawah akan ditanami padi, padi, lalu jagung. Kondisi yang heterogen ini cukup mengganggu akurasi prediksi. Perlu dilakukan penyelidikan lebih lanjut terhadap fitur yang sensitif terhadap kondisi tersebut.

Tantangan selanjutnya adalah jenis lahan pertanian di Indonesia yang cukup bervariasi antar daerah dengan petakan lahan yang cukup kecil. Posisi petakan lahan ini dapat berbeda dengan pixel citra satelit. Misalkan sentinel-2 memiliki ukuran pixel $10 \mathrm{mx} 10 \mathrm{~m}$, landsat-8 memiliki ukuran pixel $30 \mathrm{mx30m}$, sedangkan petakan sawah ada yang berukuran $100 \mathrm{~m}^{2}$, $200 \mathrm{~m}^{2}$, ataupun lebih kecil dan lebih luas. Akibat perbedaan ukuran ini, perlu pengambilan sampel yang tepat agar meningkatkan generalisasi model dalam memprediksi data yang baru.

Tantangan penting lainnya adalah perlunya dikembangkan model yang stabil untuk wilayah Indonesia yang cukup heterogen, sehingga hasil prediksi lebih akurat dan dapat dipertanggungjawabkan. Selain itu, besarnya ukuran data citra satelit menuntut untuk dikembangkan infrastruktur berbasis cloud gratis untuk mempermudah penyampaian informasi. Rata-rata cloud untuk layanan akses data dan informasi yang menyediakan tampilan langsung dari citra satelit dan analisis langsung tutupan lahan masih berbayar, seperti landviewer, CLAAS, satamap, dan aeroview.

\section{EKSPERIMEN MODEL KLASIFIKASI FASE TUMBUH PADI}

Penyelidikan lebih lanjut dari hasil eksperimen kami sendiri menggunakan RF dan data label dari hasil KSA, diperoleh bahwa pengambilan sampel, identifikasi kemungkinan seluruh kelas klasifikasi, serta fitur enginering memainkan peranan penting (Triscowati, Sartono, Kurnia, Dirgahayu, \& Wijayanto, 2019). Sampel harus tersebar secara acak dan meliputi seluruh area yang diamati agar model mampu menangkap keheterogenan wilayah. Seluruh kemungkinan kelas di lapangan harus 184 
teridentifkasi dalam model untuk meningkatkan kemampuan prediksi model. Misalkan jika area amatan di sawah, maka semua jenis tanaman dalam sawah harus teridentifikasi. Jika model hanya menangkap pola padi saja, maka otomatis tanaman non padi akan salah klasifikasi menjadi tanaman padi.

Fitur engineering merupakan kunci utama dalam pembeda jenis tanaman karena kelas klasifikasi yang berbeda membutuhkan fitur yang berbeda. Misalkan untuk membedakan kelas padi dan non padi, fitur terbaiknya adalah variasi nilai indeks vegetasi dalam 1 periode tanam. Sedangkan untuk membedakan kelas di tiap fase pertumbuhan padi, fitur tebaiknya adalah nilai maksimum dan minimum EVI dan nilai indeks vegetasi pada bulan yang bersangkutan. Hal ini berarti pemilihan fitur sangat penting. Contoh perbedaan jenis set fitur terbaik antar jenis kelas klasifikasi dapat dilihat pada gambar 1.

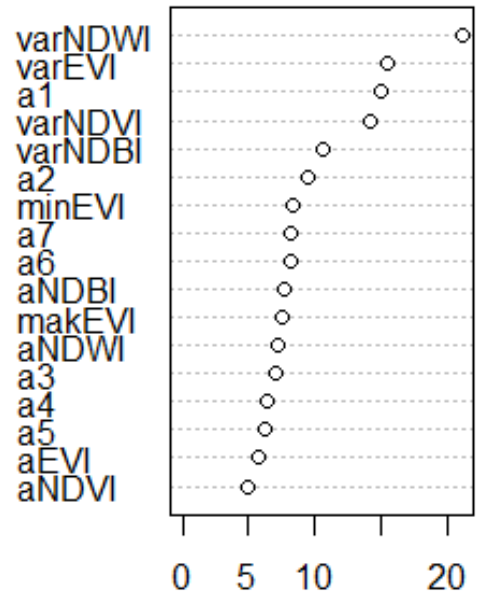

MeanDecreaseGini

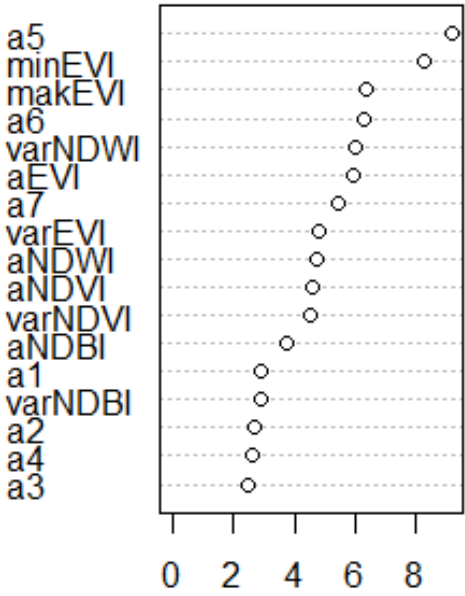

MeanDecreaseGini

Gambar 1. Temuan Fitur Pembeda Terbaik pada Model Usulan dengan Supervised Random Forest(SRF). (Kiri: Kelas Klasifikasi Padi dan Non Padi. Kanan: Kelas Klasifikasi Fase Tanam Padi)

Bagian kiri gambar 1 menunjukkan set fitur terbaik pembeda kelas sawah padi, sawah bukan padi, dan kelas sawah. Fitur yang paling mampu membedakan ketiga kelas ini adalah nilai variasi NDWI dan variasi EVI dalam 4 periode. NDWI adalah indeks yang menangkap adanya air, sementara EVI adalah indeks yang menangkap tingkat kehijauan. Jika kita kaitkan dengan pola spektral temporal antar kelas, maka dapat kita katakan bahwa nilai NDWI dan EVI pada kelas padi sangat bervariasi, sedangkan pada kelas sawah bukan padi dan bukan sawah tidak terlalu bervariasi. Pada sawah padi, saat fase awal tanam, nilai NDWI akan tinggi dan EVI masih rendah karena sawah tergenang air dan tanaman belum rapat. Memasuki fase selanjutnya, nilai NDWI akan turun dan EVI mulai naik karena genangan air berkurang dan tanaman semakin rapat.

\section{KESIMPULAN DAN SARAN}

Peluang dan tantangan penginderaan jauh dan machine learning telah dieksplorasi dalam makalah ini. Hal ini menunjukkan bahwa data citra satelit temporal, spektral, dan spasial berpotensi sebagai sumber data untuk pemantauan tanaman pangan. Namun, agar potensi ini dapat direalisasikan, perlu pengembangan metode yang efektif dan mampu menangani kondisi pertanian dan geografis di Indonesia.

Hasil prediksi citra satelit ini dapat digunakan sebagai sumber data tunggal, ataupun dipadukan dengan survei yang telah ada. Saat dipadukan dengan survei, model dapat digunakan untuk memprediksi area diluar sampel survei ataupun dijadikan faktor penimbang untuk estimasi hasil survei. Dengan perpaduan seperti itu, kita mendapatkan gambaran komprehensif perubahan kondisi seluruh area, baik area sampel melalui survei, dan area non sampel melalui citra satelit.

Beberapa rekomendasi untuk BPS adalah sebagai berikut:

a. Untuk pengembangan model klasifikasi tanaman pangan dilakukan kajian lebih mendalam dengan penambahan data training pada kelas dengan jumlah sampel yang sedikit seperti puso. 
b. Pembentukan kelas prediksi yang lebih detail dibandingkan KSA, seperti kelas generatif menjadi generatif awal dan generatif akhir, dan bera menjadi bera kering dan bera basah.

c. Pembentukan data label yang periodenya sesuai dengan periode citra satelit

d. Pengkombinasian antara citra optik dan citra radar yang mampu menembus awan

e. Untuk mengurangi waktu proses, pemodelan dapat dilakukan pada daerah yang diyakini dan diduga sebagai lahan pertanian saja. Pada lahan yang diyakini dan diduga bukan lahan pertanian, prediksi cukup dilakukan beberapa bulan sekali untuk mengevaluasi apabila sewaktu-waktu terjadi perubahan lahan menjadi lahan pertanian.

f. Pemodelan klasifikasi citra satelit ini dapat dikembangkan pada jenis klasifikasi yang lain untuk membantu penyediaan data statistik yang lebih luas. Contohnya untuk memperkirakan produksi garam, kita dapat melatih model menggunakan citra Modis harian dengan terlebih dahulu menyelidiki pancaran spektral area sekitar pantai yang merupakan tempat penjemuran garam.

\section{DAFTAR PUSTAKA}

[BPS] Badan Pusat Statistik. (2015). Pedoman Pelaksanaan Uji Coba Sistem Kerangka Sampel Area (KSA) 2015. Jakarta [ID]: BPS.

[UNDP] United Nations Development Programs. (2015). Transforming Our World: the 2030 Agenda For Sustainable Development. Washington [AS]: UNDP.

Asgarian, A., Soffianian, A., \& Pourmanafi, S. (2016). Crop Type Mapping in a Highly Fragmented and Heterogeneous Agricultural landscape: A case of Central Iran Using Multi-Temporal Landsat 8 Imagery. Computers and Electronics in Agriculture, 127, 531-540. https://doi.org/10.1016/j.compag.2016.07.019

Azar, R., Villa, P., Stroppiana, D., Crema, A., Boschetti, M., \& Brivio, P. A. (2016). Assessing In-Season Crop Classification Performance Using Satellite Data: A Test Case In Northern Italy. European Journal of Remote Sensing, 49, 361-380. https://doi.org/10.5721/EuJRS20164920

Blasiak, K. (2014). Big Data; A Management Revolution.

Clark, M. L. (2017). Comparison of Simulated Hyperspectral HyspIRI and Multispectral Landsat 8 and Sentinel2 Imagery for Multi-Seasonal, Regional Land-Cover Mapping. Remote Sensing of Environment, 200(July), 311-325. https://doi.org/10.1016/j.rse.2017.08.028

Dirgahayu, D., Parsa, I. M., \& Carolita, I. (1997). Metode klasifikasi Radar Mono Temporal (Studi Kasus Pada Tanaman Tebu). In Majalah Lapan.

Dirgahayu, D., Parsa, I. M., Silvia, Hartini, S., Budoyo, S., Indriawan, K., ... Ernawati. (2015). Litbang Pemanfaatan Data Penginderaan Jauh Untuk Pemantauan Pertumbuhan Tanaman Padi Di Lahan Sawah (Studi Kasus Pulau Kalimantan). Jakarta [ID]: Pusfatja LAPAN.

Fathoni, M. N., Chulafak, G. A., \& Kushardono, D. (2017). Kajian Awal Pemanfaatan Data Radar Sentinel-1 untuk Pemetaan Lahan Baku Sawah di Kabupaten Indramayu Jawa Barat. In Seminar Nasional Penginderaan jauh ke-4. Indonesia: Lapan.

Fritz, S., See, L., Carlos, J., Bayas, L., Waldner, F., Jacques, D., ... Mccallum, I. (2018). A Comparison Of Global Agricultural Monitoring Systems and Current Gaps. Agriculture System, (May). https://doi.org/10.1016/j.agsy.2018.05.010

Ghimire, B., Rogan, J., Galiano, V. R., Panday, P., \& Neeti, N. (2012). An Evaluation of Bagging , Boosting , and Random Forests for Land- Cover Classification in Cape Cod, Massachusetts, USA. GIScience \$ Remote Sensing, 49(5), 623-643. https://doi.org/10.2747/1548-1603.49.5.623

Guan, X., Huang, C., Liu, G., Meng, X., \& Liu, Q. (2016). Mapping Rice Cropping Systems in Vietnam Using an NDVI-Based Time-Series Similarity Measurement Based on DTW Distance. Remote Sensing, 8(19), 1-25. https://doi.org/10.3390/rs8010019

Jiang, Z., Huete, A. R., Didan, K., \& Miura, T. (2008). Development of a two-band enhanced vegetation index without a blue band. Remote Sensing of Environment, (October 2008), 13-24. https://doi.org/10.1016/j.rse.2008.06.006

Kamilaris, A., \& Bold, P. X. F. (2018). Deep Learning in Agriculture: A Survey. Computers and Electronics in Agriculture, 147(April), 70-90. https://doi.org/10.1016/j.compag.2018.02.016

Liu, Y., Zhong, Y., Fei, F., Zhu, Q., \& Qin, Q. (2018). Scene Classification Based on Multiscale Convolutional Neural Network. Remote Sensing, 10(3), 1-13. https://doi.org/10.3390/rs10030444

Lu, Q., \& Zhang, L. (2018). Learning Transferable Deep Models for Land-Use Classification with High- Learning Transferable Deep Models for Land-Use Classification with High-Resolution Remote Sensing Images * arXiv : 1807 . 05713v1 [ cs . CV ] 16 Jul 2018. NASA Astrophysics Data System (Subject Computer Vision 
and Pattern Recognition), (July).

Millard, K., \& Richardson, M. (2015). On the Importance of Training Data Sample Selection in Random Forest Image Classification: A Case Study in Peatland Ecosystem Mapping. Remote Sensing, (7), 8489-8515. https://doi.org/10.3390/rs70708489

Noviar, H., Dirgahayu, D., Anwar, S., \& Indriyawan, K. (2015). Respon Spektral Tanaman Padi Menggunakan Data Landsat-8 ( Studi Kasus Di Sulawesi Selatan ). In Seminar Nasional Penginderaan Jauh (Vol. 8, pp. 445-458). Indonesia: Lapan.

Onojeghuo, A. O., \& Blackburn, G. A. (2011). Forest transition in an ecologically important region : Patterns and causes for landscape dynamics in the Niger Delta. Ecological Indicators, 11(5), 1437-1446. https://doi.org/10.1016/j.ecolind.2011.03.017

Park, S., Im, J., Park, S., Yoo, C., Han, H., \& Rhee, J. (2018). Classification and Mapping of Paddy Rice by Combining Landsat and SAR Time Series Data. Remote Sensing, 10(447), 1-22. https://doi.org/10.3390/rs10030447

Parsa, I. M., Dirgahayu, D., Manalu, J., Carolita, I., \& KH, W. (2017). Uji Model Fase Pertumbuhan Padi Berbasis Citra Modis Multiwaktu Di Pulau Lombok. Jurnal Penginderaan Jauh, 14(1), 51-64.

Tao, Y., Xu, M., Lu, Z., \& Zhong, Y. (2018). DenseNet-Based Depth-Width Double Reinforced Deep Learning Neural Network for High-Resolution Remote Sensing Image Per-Pixel Classification. Remote Sensing, 10779). https://doi.org/10.3390/rs10050779

Thenkabail, P. S., Gumma, M. K., Teluglunta, P., \& Mohammed, I. A. (2014). Hyperspectral Hyperion Images and Spectral Libraries of Agricultural Crops. Photogrammetric Engineering and Remote Sensing, (August).

Tong, X., Xia, G., Lu, Q., Shen, H., \& Li, S. (2018). Learning Transferable Deep Models for Land-Use Classification with High-Resolution Remote Sensing Images. NASA Astrophysics Data System (Subject Computer Vision and Pattern Recognition), (July), 1-25.

Triscowati, D. W., Sartono, B., Kurnia, A., Dirgahayu, D., \& Wijayanto, A. W. (2019). Klasifikasi Fase Tanam Padi Menggunakan Supervised Random Forest Pada Data Multitemporal Citra Landsat-8. In Seminar Nasional Penginderaan Jauh.

You, J., Li, X., Low, M., Lobell, D., \& Ermon, S. (2017). Deep Gaussian Process for Crop Yield Prediction Based on Remote Sensing Data. 31th AAAI Conference on Artificial Intelligence, 4559-4565.

Zhang, L., Zhang, L., \& Du, B. (2016). Deep Learning for Remote Sensing Data. IEEE Geoscience and Remote Sensing Magazine, June(june), 22-40.

Zhu, X. X., Tuia, D., Mou, L., Xia, G. S., Zhang, L., Xu, F., \& Fraundorfer, F. (2017). Deep Learning in Remote Sensing. IEEE Geoscience and Remote Sensing Magazine, (December), 1-29. 